\title{
Genetic mutations in nonsyndromic deafness patients of Chinese minority and han ethnicities in Yunnan, China
}

Feng Xin ${ }^{1+}$, Yongyi Yuan ${ }^{1+}$, Xiaoming Deng ${ }^{3+}$, Mingyu Han ${ }^{1,2}$, Guojian Wang ${ }^{1,2}$, Jiandong Zhao ${ }^{1}$, Xue Gao , Jun Liu', Fei Yu', Dongyi Han ${ }^{1}$ and Pu Dai ${ }^{1,2^{*}}$

\begin{abstract}
Background: Each year in China, 30,000 babies are born with congenital hearing impairment. However, the molecular etiology of hearing impairment in the Yunnan Province population where more than 52 minorities live has not been thoroughly investigated. To provide appropriate genetic testing and counseling to these families, we investigated the molecular etiology of nonsyndromic deafness in this population.

Methods: Unrelated students with hearing loss $(n=235)$ who attended Kunming Huaxia secondary specialized school in Yunnan enrolled in this study. Three prominent deafness-related genes, GJB2, SLC26A4 and mtDNA 125 $r R N A$, were analyzed. High-resolution temporal bone computed tomography (CT) scan examinations were performed in 100 cases, including 16 cases with SLC26A4 gene variants, and 37 minorities and 47 Han cases without any SLC26A4 gene mutation.

Results: The GJB2 mutation was detected in 16.67\% (7/42) of minority patients and 17.62\% (34/193) of Chinese Han patients $(P>0.05)$. 235delC was the hotspot mutation in nonsyndromic hearing loss (NSHL) patients, whereas 35 delG was not found. The 431_450del19 mutation was detected for the first time in Han NSHL patients, which resulted in a premature stop codon and changed the protein. The SLC26A4 mutation was found in 9.52\% (4/42) of minority patients and 9.84\% (19/193) of Han Chinese patients ( $P>0.05)$. The frequencies of mtDNA 12S rRNA mutation in minority and Han Chinese patients were 11.90\% (5/42) and 7.77\% (15/193; P > 0.05), respectively. Sixteen (16/23, 69.57\%) patients with SLC26A4 mutations received temporal bone CT scan, and 14 patients were diagnosed with enlarged vestibular aqueducts (EVAs); the other 2 patients had normal inner ear development. The ratio of EVA in the minorities was $14.63 \%(6 / 41)$.

Conclusions: In this study, a total of $35.74 \%$ deaf patients showed evidence of genetic involvement, based on either genetic screening or family history; $17.45 \%, 9.79 \%$, and $8.51 \%$ of the patients were determined to have inherited hearing impairment caused by GJB2, SLC26A4, and mtDNA 1555A > G mutations. There was no significant difference in deafness associated gene mutational spectrum and frequency between the Yunnan minority and Han patients.
\end{abstract}

Keywords: Genetic mutations, Nonsyndromic deafness, Minority, Han, Yunnan

\footnotetext{
* Correspondence: daipu301@vip.sina.com

${ }^{\dagger}$ Equal contributors

'Department of Otolaryngology and Genetic Testing Center for Deafness,

Chinese PLA General Hospital, Beijing 100853, P.R. China

${ }^{2}$ Department of Otorhinolaryngology, Hainan Branch of PLA General Hospital,

Sanya, P.R. China

Full list of author information is available at the end of the article
} 


\section{Introduction}

Hearing impairment is the most common neurosensory disorder in humans, with an incidence of 1 in 300 to 1 in 1,000 children [1-3] and approximately half of all cases are caused by genetic defects. GJB2, SLC26A4 and mitochondrial DNA ( $m t D N A$ ) $12 S$ rRNA are thought to be the most common causes of nonsyndromic autosomal recessive deafness in Asian people. China is a large country with 1.3 billion people of 56 ethnicities. For effective genetic testing and accurate counseling, comprehensive genetic analysis in deaf patients in most Chinese regions had been performed. However, little is known of the Yunnan Province, located southeast of mainland China, where 52 nationalities-including Han and 51 minoritieslive together. Yunnan Province, which comprises more than 52 ethnic groups, is an important cradle of civilization. Among the 52 Chinese ethnicities, the 16 native to Yunnan are: Yi, Bai, Hani, Dai, Lisu, Lahu, Wa, Naxi, Jingpo, Brown, Prattm, Achang, Nu, Jino, Deang and Dulong. Data released by the Yunnan province Disabled Persons' Federation showed that $7.47 \%(477 / 6,383)$ of handicapped out-ofschool children suffered from hearing impairment.

Worldwide, the most common cause of nonsyndromic autosomal recessive hearing loss is a mutation in connexin 26, a gap-junction protein encoded by the GJB2 gene [4-11]. Defects in SLC26A4, which encodes the anion (chloride/iodide, chloride/bicarbonate) transporter Pendrin, can cause nonsyndromic DFNB4 deafness with enlargement of the vestibular aqueduct (EVA) and Pendred syndrome [12,13]. A SLC26A4 mutation is the second most common cause of deafness in China [4]. Although the majority of cases of hereditary hearing loss are caused by nuclear gene defects, it has become clear that mutations in mtDNA can also cause nonsyndromic hearing loss. The best-studied mutations related to aminoglycoside susceptibility are A1555G and C1494T in the mtDNA $12 S$ rRNA gene [14-16]. Nonsyndromic inherited hearing impairment caused by mutations in GJB2, SLC26A4, or $m t D N A 12 S$ $r R N A$ typically account for $33.8 \%$ of the cases of deafness in areas of China [17].

Connexin 26, a gap junction protein encoded by the GJB2 gene, is the most common molecular defect in nonsyndromic autosomal recessive deafness in China [4-11]. The GJB2 gene mutational site exhibits racial differences: the high-incidence mutational site is 30_35delG in Caucasians, 167delT in Jews, and 233_235delC in Japanese. The molecular epidemiological investigation of deafness in China shows that GJB2 235delC has a high prevalence in Chinese deaf populations. Among recessive mutations, 35delG is the most frequent in Caucasians, 167delT in Ashkenazi Jews, 235delC in East Asians, and R143W in Africans, suggesting the existence of founder effects in different ethnic groups [7,14-16,18-26].

In the present study, we comprehensively analyzed three prominent deafness-related genes (i.e., GJB2, SLC26A4, $m t D N A 12 S r R N A$ ) in 235 patients, including 45 minority patients from unrelated families in the Yunnan province who experienced early onset, nonsyndromic hearing impairment, to investigate the molecular etiology of hereditary hearing loss in this region. Detailed genotype and phenotype analyses were performed to provide effective risk assessment and genetic counseling for hearing loss patients and their families in this area.

\section{Materials and Methods}

\section{Patients and DNA samples}

Unrelated hearing loss patients $(n=235)$ from Huaxia secondary special education school in Yunnan province were enrolled in this study. This cohort of patients consisted of 133 males and 102 females from 17 to 23 years old, with an average age of $17.26 \pm 2.12$ years. Huaxia school is the only secondary special education school for the disabled in Yunnan, whose students come from all over the province. The ethnic minority composition in Huaxia school (30.2\%) is consistent with that of the province's. Ethnically, the patients included 193 Han (82.1\%), 13 Bai (5.5\%), 5 Dai (2.1\%), 7 Yi (3.0\%), 2 Hani (0.9\%), 3 Hui (1.3\%), 1 Jingpo (0.4\%), 2 Lahu (0.9\%), 2 Lisu (0.9\%), 5 Nazi (2.1\%), $1 \mathrm{Wa}(0.4 \%)$, and 1 Yao (0.4\%) Chinese.

The study protocol was performed with the approval of the ethnicity committee of the Chinese PLA General Hospital. Informed consent was obtained from all subjects prior to blood sampling. Parents were interviewed with regard to age of onset, family history, health of the mother during pregnancy and the clinical history of the patient, including infection, possible head or brain injury, and the use of aminoglycoside antibiotics. All subjects had moderate to profound bilateral sensorineural hearing impairment on audiograms. Careful medical examinations resulted in two patients being diagnosed with Waardenburg syndrome. DNA was extracted from the peripheral blood leukocytes of 235 patients with nonsyndromic hearing loss and 200 region- and race-matched controls with normal hearing using a commercially available DNA extraction kit (Watson Biotechnologies Inc, Shanghai, China).

\section{Mutational analysis}

The coding exons plus approximately $50-100$ bp of the flanking intron regions of GJB2, $m t D N A 12 S$ rRNA and $S L C 26 A 4$ were amplified by polymerase chain reaction (PCR), then sequenced using the Big Dye sequencing protocol in all patients. The sequence results were analyzed using an ABI 3100 DNA sequencing machine (Applied Biosystems, Foster City, CA) and ABI 3100 Analysis Software v.3.7 NT, according to the manufacturer's protocol. Patients with monoallelic GJB2 coding region mutations were further tested for GJB2 IVS1 + 1G > A mutation or defects in GJB2 exon 1 and its basal promoter. 
For all 235 patients, 20 SLC26A4 exons were individually sequenced starting from the frequently mutated exons 7, 8, 10 and 19. Patients with a single mutation on the above four exons were screened for the other exons in SLC26A4.

Two hundred controls with normal hearing were sequenced to determine the presence of mutations in the GJB2 and $m t D N A 12 S$ rRNA polymorphisms. In addition, all controls were screened for SLC26A4 mutations by denaturing high-pressure liquid chromatography (DHPLC) followed by sequencing.

\section{CT scan and thyroid examination}

A total of 100 patients, including 16 cases with variants in SLC26A4, 37 minority patients and 47 Han cases without any mutations or variants in SLC26A4, were examined using temporal bone CT scans to diagnose EVA. EVA diagnosis was based on findings of a diameter of $>1.5 \mathrm{~mm}$ at the midpoint between the common crus and the external aperture [27] or other inner ear malformations to evaluate Pendred syndrome. Thyroid ultrasound scans and thyroid hormone level determination was performed in patients with SLC26A4 mutations or variants. These procedures were performed at the Frist Hospital of Yunnan province, China. As perchlorate discharge testing is not a general clinical practice in China, it was not used in this study.

\section{Statistical method}

The statistical analysis was performed using SPSS 15.0 software (statistica package for the Social Sciences). The intergroup difference in frequency was compared using the two-tailed chi-square test. A P-value less than 0.05 was considered statistically significant.

\section{Results \\ GJB2}

Our sequence analysis of the GJB2 gene indicated that 34 patients carried two confirmed pathogenic mutations, including 25 homozygotes and 9 compound heterozygotes. Seven patients carried one heterozygous pathogenic mutation without an identified second mutant allele (Table 1). Thus, $17.45 \%(41 / 235)$ of the patients had molecular defects in GJB2, which is similar to the ratio of typical areas in China $\left(18.31 \%\right.$; $\chi^{2}=0.0651$, $\mathrm{P}>0.05)$. Thus, GJB2 mutant alleles accounted for $16.0 \%$ $(75 / 470)$ of the total alleles in $235 \mathrm{NSHI}$ patients. Of those patients, $14.45 \%(34 / 235)$ had confirmed molecular etiology, and $2.98 \%$ (7/235) carried only one pathogenic mutation. The most common mutant allele was c.235delC, followed by c.299_300delAT, c.512insAACG, c.139G > T and c.176del16, which accounted for $11.1 \%$ (52/470), 1.7\% (8/470), $1.1 \%(5 / 470), 0.6 \%(3 / 470)$ and $0.6 \%(3 / 470)$, respectively.

c.235delC was the hotspot in this patient cohort, which reportedly is the most prevalent mutation in East Asian and Southeast Asian populations, but is not common in European or Oceania populations [28]. Twenty patients were homozygous for the c. $235 \mathrm{delC}$ mutation, seven were compound heterozygous with another pathogenic mutation, and five were heterozygous for the c.235delC mutation (Table 1). One novel frameshift

Table 1 Genotypes of patients with mutations in the GJB2 gene

\begin{tabular}{|c|c|c|c|c|c|c|}
\hline \multicolumn{3}{|l|}{ Allele1 } & \multicolumn{4}{|l|}{ Allele2 } \\
\hline Nucleotide change & $\begin{array}{l}\text { Consequence or } \\
\text { amino change }\end{array}$ & Category & Nucleotide change & $\begin{array}{l}\text { Consequence or } \\
\text { amino change }\end{array}$ & Category & $\begin{array}{l}\text { Number of } \\
\text { patients }\end{array}$ \\
\hline c.235delC & Frameshift & Pathogenic & c.235delC & Frameshift & Pathogenic & 20 \\
\hline c.139G > T & Glu at 47 into Stop & Pathogenic & c.139G > T & Glu at 47 into Stop & Pathogenic & 1 \\
\hline c.176del16 & Frameshift & Pathogenic & c.176del16 & Frameshift & Pathogenic & 1 \\
\hline c.299del AT & Frameshift & Pathogenic & c.299delAT & Frameshift & Pathogenic & 2 \\
\hline c.512insAACG & Frameshift & Pathogenic & c.512insAACG & Frameshift & Pathogenic & 1 \\
\hline c.235delC & Frameshift & Pathogenic & c.299delAT & Frameshift & Pathogenic & 3 \\
\hline c.176del16 & Frameshift & Pathogenic & c.235delC & Frameshift & Pathogenic & 1 \\
\hline c.235delC & Frameshift & Pathogenic & c.512insAACG & Frameshift & Pathogenic & 1 \\
\hline c.35insG & Frameshift & Pathogenic & c.512insAACG & Frameshift & Pathogenic & 1 \\
\hline c.139G > T & Glu at 47 into Stop & Pathogenic & c.299delAT & Frameshift & Pathogenic & 1 \\
\hline$c .9 G>A$ & & Pathogenic & c.235delC & Frameshift & Pathogenic & 1 \\
\hline c. $11 \mathrm{G}>\mathrm{A}$ & & Pathogenic & c.235delC & Frameshift & Pathogenic & 1 \\
\hline c.235delC & Frameshift & Pathogenic & & & & 5 \\
\hline c.512insAACG & Frameshift & Pathogenic & & & & 1 \\
\hline c.431-450del19 & Novel & & & & & 1 \\
\hline
\end{tabular}


mutation was identified, 431_450del19 (Table 1). Overall, 75 mutant alleles (including the unclassified missense variants) were identified in 41 unrelated patients. c.235delC alone accounted for $69.33 \%(52 / 75)$ of the total mutant alleles, compared to $71.64 \%(96 / 134)$ in typical areas of China [17], 69.18\% (101/146) in northern China [29]. The differences were not significant among ours and other studies of the Chinese population $\left(\chi^{2}=\right.$ 0.1240, $X^{2}=0.0006, \mathrm{P}>0.05$ ).

The GJB2 mutation frequency was $16.67 \%$ (7/42) in minority patients, involving two mutations (i.e., c.235delC and c.139G > T) whose allele frequencies were 14.29\% (12/ 84 ) and $2.38 \%(2 / 84)$, respectively. Of all the 20 homozygous c.235delC patients, three $\mathrm{Yi}$, two $\mathrm{Bai}$, and one Hui patient were homozygous for c.235delC. One Dai patient carried homozygous c.139G $>\mathrm{T}$. The GJB2 mutation frequency in Han Chinese patients was 17.62\% (34/ 193), involving nine mutations: c. 235delC, c.299de1AT, c.512insAACG, c.176del16, c.35insG, c.139G > T, c.9G > A, c.11G > A, c.431_450del19. The allele frequencies were $10.36 \%$ (40/386), $2.07 \%$ (8/386), $1.30 \%$ (5/386), $0.78 \%$ (3/386), $0.26 \%$ (1/386), $0.26 \%$ (1/386), $0.26 \%$ (1/386), $0.26 \%(1 / 386)$ and $0.26 \%(1 / 386)$ in Han Chinese patients, respectively. The c.235delC allele frequency in the minority patients was not significantly different from that in the Han patients $\left(X^{2}=1.0790, P>0.05\right)$.

We analyzed the GJB2 gene in 200 control subjects with normal hearing and found three types of deleterious mutations, c.235delC, c.299_300delAT and c.139G > T, carried by seven subjects in the heterozygous state. This suggested a GJB2 mutation carrier rate of $\sim 3.5 \%$ (7/200) in the general population. Meanwhile, the carrier rates of the GJB2 mutation in Korea, Japan, Taiwan, Ashkenazi Jews and in the Midwestern United States are reported to be $2 \%, 2.08 \%, 2.55 \%, 4.76 \%$, and $3.01 \%$, respectively [5,20,21,30-32].

\section{mtDNA 125 rRNA}

Eight and a half percent (20/235) of patients carried the $m t D N A 12 S$ rRNA $1555 \mathrm{~A}>\mathrm{G}$ mutation. Among the 20 patients, 7 had a clear history of aminoglycoside use. The frequency of $1555 \mathrm{~A}>\mathrm{G}$ mutation was $7.77 \%(15 / 193)$ in Han patients and $11.90 \%(5 / 42)$ in minority patients. The five minority patients consisted of two Bai, one Naxi, one Hani and one Hui. None of the 200 control subjects were found to carry the 1555A > G mutation.

\section{SLC26A4}

Sequence analysis of the SLC26A4 gene in these 235 patients identified nine patients with two confirmed pathogenic mutations, and five patients carried one confirmed pathogenic mutation. Six patients were compound heterozygous for one pathogenic mutation and one unclassified variant, and three patients carried one unclassified variant (Table 2). Thus, mutations in SLC26A4 were identified in $9.97 \%(23 / 235)$ of patients with hearing impairment in this study.

A total of seven different pathogenic mutations (IVS7$2 \mathrm{~A}>\mathrm{G}$, c.2168A $>$ G, c.84C > A, c.1975G > C, c.754 T>C, c.1548insG, IVS9 $+1 \mathrm{G}>\mathrm{A}$ ) and six unclassified variants (intro6-75_76insTGTG, IVS11 + $47 \mathrm{~T}>\mathrm{C}$, c.2265C $>\mathrm{A}$, IVS5 + 27 T $>$ C, IVS7 + 35A $>$ G, IVS7 + 40G > A) were found (Table 2). The c.1548insG mutation resulted in a premature stop codon and a truncated protein with only 526 amino acid residues. For those mutations, IVS7-2A > G, c.2168A > G, c.84C > A, c.1975G > C, c.754 T > C and IVS $9+1 \mathrm{G}>\mathrm{A}$, were previously reported in patients with hearing loss [33-38]. For other variants, IVS11 $+47 \mathrm{~T}>\mathrm{C}$, c. $2265 \mathrm{C}>\mathrm{A}, \quad$ IVS5 + 27 T > C, IVS7 + 35A > G, IVS7 + 40G > A and intro6-75-76insTGTG, the NNSPLICE software, available at http://www.fruitfly.org/seq_tools/splice. html was used for analysis. The results indicated that those variants did not predict gain or loss of a splice site with this variant, and those variants were considered benign. Thus, SLC26A4 mutant alleles accounted for $82.61 \%$ $(38 / 46)$ of the total alleles in $235 \mathrm{NSHI}$ patients. For those patients, $43.48 \%(10 / 23)$ had a confirmed molecular etiology, and $43.48 \%(10 / 23)$ carried only one pathogenic mutation.

IVS7-2A > G was the hotspot mutation region in this patient cohort, for which five patients were homozygous, six were compound heterozygous, and four were heterozygous (Table 2). One of the four patients with the heterozygous IVS7-2A $>$ G mutation was also homozygous for the GJB2 c.235delC mutation. Thus, this patient may be only an IVS7-2A > G carrier, with defects in GJB2 being the main cause of hearing loss. The IVS7-2A $>$ G mutation accounted for $64.63 \%$ (53/82, counting only the definite pathogenic and most likely pathogenic variants) of all SLC26A4 mutant alleles in this population.

The SCL26A4 mutation frequency was $9.52 \%(4 / 42)$ in minority patients, involving six mutations: IVS7-2A > G, c.intron6-75_76insTGTG, c.2168A > G, c.84A> G, c. IVS11 $+47 \mathrm{~T}>\mathrm{C}$ and c.1548insG. One Hui carried IVS7-2A > G/IVS7-2A > G, one Yi carried IVS7-2A > G/ 1548insC, one Bai carried IVS7-2A $>$ G/IVS5 $+27 \mathrm{~T}>\mathrm{C}$ and one Zhuan carried IVS11 $+47 \mathrm{~T}>\mathrm{C} / 1548$ insC. The allele frequencies were $2.38 \%(2 / 84), 1.19 \%(1 / 84)$, $1.19 \%(1 / 84), 1.19 \%(1 / 84), 1.19 \%(1 / 84)$ and $1.19 \%(1 / 84)$ for IVS7-2A > G, c.intron6-75_76insTGTG, c.2168A > G, c.84A > G, IVS11 + $47 \mathrm{~T}>\mathrm{C}$ and c.1548insG, respectively. For the Han Chinese population, SLC26A4 mutation frequency was 9.84\% (19/193), involving 11 mutations: IVS7-2A > G, c.2168A > G, c.1079 T>C, c.1975G > C, c.754 T > C, IVS9 + 1G > A, IVS11 + 47 T $>$ C, c. $2265 C>$ A, IVS5 + 27 T $>$ C, IVS7 + 35A $>$ G and IVS7 + 40G > A. The allele frequencies were $6.64 \%(19 / 286)$ for IVS7-2A > G, 1.05\% (3/286) for c.2168A > G, 0.70\% (2/ 
Table 2 Genotypes of SLC26A4 gene-related hearing impairment in Yunnan

\begin{tabular}{|c|c|c|c|c|c|c|c|}
\hline Allele1 & & & Allele2 & & & & \\
\hline Nucleotide change & $\begin{array}{l}\text { Consequence or } \\
\text { amino change }\end{array}$ & Category & Nucleotide change & $\begin{array}{l}\text { Consequence or } \\
\text { amino change }\end{array}$ & Category & & \\
\hline c.IVS7-2A > G & aberrant splicing & Pathogenic & c.IVS7-2A $>G$ & aberrant splicing & Pathogenic & 4 & EVA \\
\hline c.IVS7-2A $>G$ & aberrant splicing & Pathogenic & c.IVS7-2A $>G$ & aberrant splicing & Pathogenic & 1 & $\mathrm{nl}$ \\
\hline c.IVS7-2A $>G$ & aberrant splicing & Pathogenic & c.754 T > C & S252P & Pathogenic & 1 & ND \\
\hline c.IVS7-2A $>G$ & aberrant splicing & Pathogenic & c.1548insC & FX517,526X & Pathogenic & 1 & EVA \\
\hline c. $2168 A>G$ & $\mathrm{H} 723 \mathrm{R}$ & Pathogenic & c.1079 T>C & A360V & Pathogenic & 1 & EVA \\
\hline c. $2168 A>G$ & $\mathrm{H} 723 \mathrm{R}$ & Pathogenic & C. $84 C>A$ & S28R & Pathogenic & 1 & $\mathrm{nl}$ \\
\hline c.IVS7-2A $>G$ & aberrant splicing & Pathogenic & c. $1975 G>C$ & V659L & Pathogenic & 1 & EVA \\
\hline c.IVS7-2A > G & aberrant splicing & Pathogenic & c.lVS9 + 1G>A & aberrant splicing & Pathogenic & 2 & EVA \\
\hline c.IVS7-2A > G & aberrant splicing & Pathogenic & c. $2265 C>A$ & T755T & Silent variant & 1 & EVA \\
\hline c.IVS7-2A > G & aberrant splicing & Pathogenic & c.IVS5 + $27 \mathrm{~T}>\mathrm{C}$ & Variant in intron & Unclassified variant & 1 & EVA \\
\hline c.1548insC & FX517,526X & Pathogenic & c.IVS11 + 47 T>C & Variant in intron & Unclassified variant & 1 & EVA \\
\hline$c .2168 A>G$ & $\mathrm{H} 723 \mathrm{R}$ & Pathogenic & & & & 1 & EVA \\
\hline c.IVS7-2A > G & aberrant splicing & Pathogenic & & & & 3 & $\mathrm{nl}$ \\
\hline c.IVS7-2A > G & aberrant splicing & Pathogenic & & & & 1 & EVA \\
\hline c.intron6-75_ 76 insTGTG & aberrant splicing & Unclassified variant & & & & 1 & $\mathrm{nl}$ \\
\hline c.IVS7 + 35A > G & Variant in intron & Unclassified variant & & & & 1 & $\mathrm{nl}$ \\
\hline c.IVS7 $+40 G>A$ & Variant in intron & Unclassified variant & & & & 1 & $\mathrm{nl}$ \\
\hline WT & & & WT & & & 2 & EVA \\
\hline
\end{tabular}

nl, normal; EVA, enlarged vestibular aqueduct; IVS7, intravening sequence7(intron 7); IVS9, intravening sequence9(intron 9); IVS5, intravening sequence5(intron 5); IVS11, intravening sequence11(intron 11); WT, wildtype.

286) for IVS11 + $47 \mathrm{~T}>\mathrm{C}$ and $0.35 \%$ (1/286) for each else.

\section{Temporal bone CT scan}

A total of 100 cases, comprised of 16 cases with SLC26A4 mutations (12 Han Chinese patients and four minority patients) and 84 control cases without any SLC26A4 mutations or variants (37 minority cases and 47 Han Chinese patients), were examined by temporal bone CT scan. Bilateral EVA was detected in 16 patients (14 patients with SLC26A4 mutation, 2 without SLC26A4 mutation) (Table 2). Four patients carried a homozygous IVS7-2A > G mutation, five carried a compound heterozygous IVS7-2A > G/1548insC, 2168A > G/84C > A, IVS7$2 \mathrm{~A}>\mathrm{G} / \mathrm{IVS} 9+1 \mathrm{G}>\mathrm{A}$ and IVS7-2A $>\mathrm{G} / 1975 \mathrm{G}>\mathrm{C}$, and five carried only one pathogenic mutation(IVS7-2A $>\mathrm{G}$, 1548ins C and 2168A > G); another two were from the minority control patients without any SLC26A4 mutations or variants. Temporal CT scan results were normal in the remaining patients (Table 2 ).

Regarding race, six minority patients (one Hui, one Bai, one Zhuang, and three Yi) presented with EVA. Four $(4 / 42,9.52 \%)$ of six patients carried a SLC26A4 mutation, whose genotypes were: IVS7-2A > G/IVS7-2A > G, IVS7$2 \mathrm{~A}>\mathrm{G} / \mathrm{IVS} 5+27$ T $>$ C, $\quad$ IVS11 + 47 T $>$ C/1548insC, 2168A $>$ G/84C $>$ A. The EVA ratio in the Chinese deaf population was at least $11 \%$, and that in patients of Han ethnicity reached at least $13 \%$.

\section{Discussion}

Many hearing loss-related gene mutations have been described to date, most of which are isolated mutations in some populations. In this study, mutation analysis was performed in 235 patients with moderate to profound sensorineural hearing loss. A total of $35.74 \%$ deaf patients showed evidence of genetic involvement based on either genetic screening or family history, and $17.45 \%$, $9.79 \%$, and $8.51 \%$ of the patients were determined to have inherited hearing impairment caused by GJB2, $S L C 26 A 4$, and $m t D N A 1555 A>G$ mutations. GJB2 mutation was detected in $16.67 \%$ (7/42) of minority patients and $17.62 \%(34 / 193)$ of Han Chinese patients. SLC26A4 mutation was found in $9.52 \%(4 / 42)$ of minority patients and $9.84 \%(19 / 193)$ of Han Chinese patients. The frequencies of $m t D N A 12 S$ rRNA mutation in minority and Han Chinese patients were $11.90 \%$ (5/42) and $7.77 \%$ (15/193). There was no significant difference in deafness associated gene mutational spectrum or frequency between the Yunnan minority patients and the Han patients (Table 3 ). These results will facilitate effective risk assessment and genetic counseling for hearing loss patients and their families in Yunnan. 
Table 3 Prevalence of GJB2, SLC26A4 and mtDNA 1555A > G mutation in the Asian

\begin{tabular}{|c|c|c|c|c|c|}
\hline \multirow[t]{2}{*}{ Different areas } & \multirow{2}{*}{$\begin{array}{l}\text { Patients' } \\
\text { number }\end{array}$} & \multicolumn{3}{|c|}{ Prequency of pathologic variants (\%) } & \multirow[t]{2}{*}{ References } \\
\hline & & GJB2 & SLC26A4 & mtDNA $1555 A>G$ & \\
\hline \multirow[t]{2}{*}{ Typical areas of China } & \multirow[t]{2}{*}{284} & $18.31 \%$ & $13.73 \%$ & $1.76 \%$ & \multirow[t]{2}{*}{ Yuan YY et al. [17] } \\
\hline & & $(52 / 284)$ & $(39 / 284)$ & $(5 / 284)$ & \\
\hline Yunnan & \multirow[t]{2}{*}{42} & $16.67 \%$ & $9.52 \%$ & $11.90 \%$ & \multirow[t]{2}{*}{ This study } \\
\hline (minority) & & $(7 / 42)$ & $(4 / 42)$ & $(5 / 42)$ & \\
\hline Yunnan & \multirow[t]{2}{*}{193} & $17.62 \%$ & $9.84 \%$ & $7.77 \%$ & \multirow[t]{2}{*}{ This study } \\
\hline (Han Chinese) & & $(34 / 193)$ & $(19 / 193)$ & $(15 / 193)$ & \\
\hline Tibet & \multirow[t]{2}{*}{114} & & & $1.75 \%$ & \multirow[t]{2}{*}{ Yuan YY et al. [40] } \\
\hline (Tibetan) & & & & $(2 / 114)$ & \\
\hline Xinjiang & \multirow[t]{2}{*}{199} & $9.05 \%$ & $2.01 \%$ & $1.51 \%$ & \multirow[t]{2}{*}{ Chen $Y$ et al. [41] } \\
\hline (Uyghur) & & $(18 / 199)$ & $(4 / 199)$ & $(3 / 199)$ & \\
\hline \multirow[t]{2}{*}{ Korea } & \multirow[t]{2}{*}{1256} & $1.91 \%$ & & & \multirow[t]{2}{*}{ Kim SY et al. [42] } \\
\hline & & $(24 / 1256)$ & & & \\
\hline \multirow[t]{2}{*}{ Japan } & \multirow[t]{2}{*}{1343} & $14.2 \%$ & & & \multirow[t]{2}{*}{ Tsukada K et al. [43] } \\
\hline & & $(1911 / 1343)$ & & & \\
\hline
\end{tabular}

\section{GJB2}

Sequencing of the GJB2 gene coding region revealed that $14.45 \%(34 / 235)$ of the patients carried two pathogenic GJB2 mutations and $2.98 \%(7 / 235)$ carried only one mutant allele. There was no significant difference between our results and the report of Dai $\left(\chi^{2}=0.0285, X^{2}=3.6975\right.$, $\mathrm{P}>0.05)$ of 2,063 unrelated NSHI students from 23 regions of China (14.9\% had two pathogenic GJB2 mutations and $6.1 \%$ carried only one mutant allele) [39].

The 235delC mutation was markedly associated with the risk of NSHL in East Asian and Southeast Asian populations, but not significantly in European or Oceanian populations [28]. In our study, the most common mutation was c. $235 \mathrm{delC}$, followed by c.299delAT. The common Caucasian mutation c.35delG was not found. Two mutations, c.235delC and c.299delAT, accounted for $80.00 \%$ $(60 / 75)$ of the GJB2 mutations in our patients, $97 \%$ in a Taiwanese population, and $91 \%$ in another Chinese population.

The 235delC allele frequency in the Yunnan minority patients (14.29\%) was not significantly different from that in the Han patients $\left(10.36 \%, X^{2}=1.0790, P>0.05\right)$, but was higher than that in Tibetan $\left(1.28 \%, \chi^{2}=78.2067\right.$, $\mathrm{P}<0.05)$ [40], Uyghur (3.52\%, $\left.\mathrm{X}^{2}=227.6810, \mathrm{P}<0.05\right)$ [41], Korean (0.44\%, $\left.\chi^{2}=116.7899, \mathrm{P}<0.05\right)$ [42], and Japanese patients $\left(5.29 \%, X^{2}=458.1409, \mathrm{P}<0.05\right)$ [43].

c.512insAACG and c.9G $>$ A were first reported in China by Dai. c.512insAACG is a pathogenic alteration with an allele frequency of $0.58 \%(12 / 2,063)$ in the Chinese population. In our study, three patients carried c.512insAACG (one homozygote, two compound heterozygotes, and one heterozygote). c.11G > A accounted for $0.43 \%(1 / 235)$ in Yunnan, $10.6 \%$ of Taiwanese GJB2 [7,31].
c.9G > A, which was a nonsense mutation, carried by one patient $0.43 \%(1 / 235)$ in Yunnan.

In addition to these mutations, we found a novel frameshift mutation, c.431_450del 19, in a heterozygous patient. This mutation was not detected in the control group. The mutation resulted in a premature stop codon. It is highly likely to be pathogenic. Regretfully, we failed to take the history and blood sample from the family members of the patient, so it is not clear whether c.431_450del 19 represents an autosomal dominant mutation or is an autosomal recessive with an unidentified second mutant allele in either the same gene or in a different gene. To clarify the exact roles of the mutation, careful follow-up and functional studies are needed.

\section{SLC26A4}

Mutations in SLC26A4, which encodes Pendrin, are a common cause of deafness, and responsible for both syndromic and nonsyndromic hearing loss. The SLC26A4 mutation spectrum varies widely among ethnic groups. In our study population, mutations in SLC26A4 were identified in $9.79 \%(23 / 235)$ of individuals, which was lower than that in typical areas of China $\left(18.66 \%, x^{2}=8.1030\right.$, $\mathrm{P}<0.05)$, but higher than that in Uyghur patients $\left(2.01 \%, X^{2}=11.1711, P<0.05\right)$ [41]. In addition, prevalent mutations in different ethnic groups are very different. The SLC26A4 mutational spectrum in Yunnan is similar to that reported in the overall Chinese population, with IVS7-2A > G being the hotspot mutation. This mutation spectrum was different from that in Japanese, Korean, northern European and Danish populations. In Japan, H723R is the most prevalent mutation. In Korea, IVS7-2A $>\mathrm{G}$ and H723R are the two most prevalent 
mutations $[44,45]$. There seems to be a shift in mutation from IVS7-2A > G to H723R from China to Japan, with Korea in the middle. This observation suggests that IVS7$2 \mathrm{~A}>\mathrm{G}$ and H723R mutations may be ancient mutations in China and Japan, respectively. The unique rare mutations evolved more recently. A recent study of 100 unrelated patients with EVA in European Caucasians by Albert et al. revealed a diverse mutation spectrum without prevalent mutations; only 40 patients carried SLC26A4 mutations [46]. It is not clear why the mutations in SLC26A4 account for a much lower percentage of patients with EVA in Caucasian patients. Presumably, other genetic factors and environmental factors are involved in the pathogenesis of EVA in Caucasians. A recent study of 109 unrelated probands with EVA in a Danish population revealed that the most frequent mutation was $1246 \mathrm{~A}>\mathrm{C}$. This implies that Danish and Chinese populations are of different ancestry [47].

In our study population, the frequency of SCL26A4 mutation was $9.52 \%$ in minority patients, which was not different from that of Han patients (9.84\%; $\chi^{2}=0.0498$, $\mathrm{P}>0.05)$. The allele frequencies of hotspot mutation, IVS7-2A > G, were $2.38 \%$ and $6.64 \%$ for minority and Han populations, respectively. The difference may due to the relatively small sample size.

It is interesting to note that eight patients with inner ear malformations carried one pathogenic mutation, and two patients with inner ear malformations carried no pathogenic mutation in SLC26A4. If SLC26A4 defects are the cause of the phenotype of inner ear malformation, pathogenic mutations may be located in introns or promoter regions that were not sequenced. Unknown genes or even environmental factors may contribute to the malformation.

\section{mtDNA $12 \mathrm{~S}$ rRNA}

MtDNA $12 S$ rRNA A1555G mutation was detected in nearly $8.51 \%(20 / 235)$ of our nonsyndromic hearing impaired population. The mutation in minority patients was not different from that of Han patients. However, the mutation rate in Yunnan deaf population was much higher than that in typical areas of China (1.76\%) according to Yuan et al. This mutation is found in approximately $3 \%$ of Japanese, $0.5-2.4 \%$ of Caucasian living in Europe or America and 5.3\% of Indonesian sensorineural deafness patients [48]. But close to the Guo' research in northern China $(8.56 \% 44 / 514)$ [29]. This is probably due to two reasons. First, Yunnan is in the southwest of China, where the overall quality of medical care is lower than the average in China; aminoglycoside antibiotic abuse exists. Second, there may be a founder effect. Northern Chinese are derived largely from the Mongolian lineage, which is quite different from the ancestor(s) of Caucasians in European countries.
Our results showed no significant difference in common deafness genes' mutational frequencies or spectrum between the minority patients and the Han patients from Yunnan Province $\left(X^{2}=0.3189, P>0.05\right)$. However, the number of individuals included from the non-Han population may have been too small to draw any conclusions. On the basis of our findings, we recommend that elective genetic testing be performed in newborns, pregnant females, or patients requiring the administration of aminoglycoside antibiotics to prevent hearing loss in Yunnan province.

\section{Conclusion}

A total of $35.74 \%$ deaf patients showed evidence of genetic involvement, based on either genetic screening or family history, and $17.45 \%, 9.79 \%$, and $8.51 \%$ of these patients were determined to have inherited hearing impairment caused by GJB2, SLC26A4, and mtDNA 1555A > G mutations. Our study showed that there was no significant difference between Yunnan minority patients and the Han patients in the deafness-associated gene mutation spectrum. Our study provides much-needed information regarding deafness molecular epidemiology of the Yunnan province, providing a rationale for deafness gene diagnosis in Yunnan province.

\section{Abbreviations \\ CT: Computed tomography; NSHL: Nonsyndromic hearing loss; EVAs: Enlarged vestibular aqueducts; mtDNA: Mitochondrial DNA; PCR: Polymerase chain reaction; DHPLC: Denaturing high-pressure liquid chromatography.}

\section{Competing interests}

The authors declare that they have no competing interests.

\section{Authors' contributions}

$F X, Y Y$, and $X D$ carried out the molecular genetic studies and participated in sequence alignment. $F X$ and $Y Y$ drafted the manuscript. $X G$ and $G W$ carried out temporal CT scan and thyroid hormone assays. JZ, FY and MH participated in sequence alignment and performed the statistical analyses. $J \mathrm{~L}$ and $\mathrm{DH}$ participated in the design of the study. PD and $Y Y$ conceived the study, participated in its design and coordination, and helped draft the manuscript. All authors have read and approved the final manuscript.

\section{Acknowledgments}

We thank all of the normal-hearing subjects who participated in this study. This work was supported by grant from the Minister of Science and Technology (2012BAI09B02) and Key Projects in the National Science \& Technology Pillar Program during the Twelfth Five-year Plan Period (2012BAl12B00/2012BAl12B01), Chinese National Nature Science Foundation Research Grant (30728030, 31071109, 81230020), and State 863 High Technology R\&D Key Project of China(SQ2010AA0221634001) to Dr. Pu Dai, Chinese National Nature Science Foundation Research Grant (81371098), Beijing Natural Science Foundation(7132177), Beijing Nova programme (2009B34) to Dr. Yongyi Yuan, PLA General Hospital Culturing Foundation (12KMM32) to Dr.Jiandong Zhao, Chinese National Nature Science Foundation Research Grant (81000415), Beijing Nova programme (2010B081) and State 863 High Technology R\&D Key Project of China(2012AA020101) to Dr. Guojian Wang, Chinese National Nature Science Foundation Research Grant (81070792) to Dr. Dongyi Han, Beijing Capital public health programs fostering (Z131100004013019) and PLA General Hospital Culturing Foundation (2012FC-TSYS-4017) to Dr. Liu Jun. 


\section{Author details}

${ }^{1}$ Department of Otolaryngology and Genetic Testing Center for Deafness, Chinese PLA General Hospital, Beijing 100853, P.R. China. ${ }^{2}$ Department of Otorhinolaryngology, Hainan Branch of PLA General Hospital, Sanya, P.R. China. ${ }^{3}$ Department of Otorhinolaryngology, First Hospital, Yunnan 650032, P.R. China. ${ }^{4}$ Department of Otolaryngology, The Second Artillery General Hospital, 16\# Xin Wai Da Jie, Beijing 100088, P.R. China.

Received: 24 September 2013 Accepted: 11 December 2013

Published: 17 December 2013

\section{References}

1. Downs MP: Universal newborn hearing screening-the Colorado story. Int J Pediatr Otorhinolaryngol 1995, 32:257-259.

2. Mehl AL, Thomson V: Newborn hearing screening: the great omission. Pediatrics 1998, 101:E4.

3. Mehl AL, Thomson V: The Colorado newborn hearing screening project, 1992-1999: on the threshold of effective population-based universal newborn hearing screening. Pediatrics 2002, 109:E7.

4. Wilcox SA, Saunders K, Osborn AH, Arnold A, Wunderlich J, Kelly T, Collins V, Wilcox LJ, McKinlay Gardner RJ, Kamarinos M, et al: High frequency hearing loss correlated with mutations in the GJB2 gene. Hum Genet 2000, 106:399-405.

5. Park HJ, Hahn SH, Chun YM, Park K, Kim HN: Connexin26 mutations associated with nonsyndromic hearing loss. Laryngoscope 2000, 110:1535-1538.

6. Rabionet R, Zelante L, Lopez-Bigas N, D'Agruma L, Melchionda S, Restagno G, Arbones ML, Gasparini P, Estivill X: Molecular basis of childhood deafness resulting from mutations in the GJB2 (connexin 26) gene. Hum Genet 2000, 106:40-44.

7. Ohtsuka A, Yuge I, Kimura S, Namba A, Abe S, Van Laer L, Van Camp G, Usami S: GJB2 deafness gene shows a specific spectrum of mutations in Japan, including a frequent founder mutation. Hum Genet 2003, 112:329-333.

8. Estivill X, Fortina P, Surrey S, Rabionet R, Melchionda S, D'Agruma L, Mansfield E, Rappaport E, Govea N, Mila M, et al: Connexin-26 mutations in sporadic and inherited sensorineural deafness. Lancet 1998, 351:394-398.

9. Lench N, Houseman M, Newton V, Van Camp G, Mueller R: Connexin-26 mutations in sporadic non-syndromal sensorineural deafness. Lancet 1998, 351:415.

10. Gabriel H, Kupsch P, Sudendey J, Winterhager E, Jahnke K, Lautermann J: Mutations in the connexin26/GJB2 gene are the most common event in non-syndromic hearing loss among the German population. Hum Mutat 2001, 17:521-522.

11. Dai P: Prevention and interdiction on hereditary deafness. Zhonghua $Y_{i}$ Xue Za Zhi 2007, 87:2811-2813.

12. Everett LA, Morsli H, Wu DK, Green ED: Expression pattern of the mouse ortholog of the Pendred's syndrome gene (Pds) suggests a key role for pendrin in the inner ear. Proc Natl Acad Sci U S A 1999, 96:9727-9732.

13. Royaux IE, Suzuki K, Mori A, Katoh R, Everett LA, Kohn LD, Green ED: Pendrin, the protein encoded by the Pendred syndrome gene (PDS), is an apical porter of iodide in the thyroid and is regulated by thyroglobulin in FRTL-5 cells. Endocrinology 2000, 141:839-845.

14. Lerer I, Sagi M, Malamud E, Levi H, Raas-Rothschild A, Abeliovich D: Contribution of connexin 26 mutations to nonsyndromic deafness in Ashkenazi patients and the variable phenotypic effect of the mutation 167delT. Am J Med Genet 2000, 95:53-56.

15. Gasparini P, Rabionet R, Barbujani G, Melchionda S, Petersen M, BrondumNielsen K, Metspalu A, Oitmaa E, Pisano M, Fortina P, et al: High carrier frequency of the $35 \mathrm{delG}$ deafness mutation in European populations. Genetic Analysis Consortium of GJB2 35delG. Eur J Hum Genet 2000, 8:19-23.

16. Kudo T, Ikeda K, Kure S, Matsubara Y, Oshima T, Watanabe K, Kawase T, Narisawa K, Takasaka T: Novel mutations in the connexin 26 gene (GJB2) responsible for childhood deafness in the Japanese population. Am J Med Genet 2000, 90:141-145.

17. Yuan Y, You Y, Huang D, Cui J, Wang Y, Wang Q, Yu F, Kang D, Yuan H, Han D, Dai P: Comprehensive molecular etiology analysis of nonsyndromic hearing impairment from typical areas in China. J Trans/ Med 2009, 7:79.

18. Van Laer L, Coucke P, Mueller RF, Caethoven G, Flothmann K, Prasad SD, Chamberlin GP, Houseman M, Taylor GR, Van de Heyning CM, et al:
A common founder for the 35 delG GJB2 gene mutation in connexin 26 hearing impairment. J Med Genet 2001, 38:515-518.

19. Brobby GW, Muller-Myhsok B, Horstmann RD: Connexin 26 R143W mutation associated with recessive nonsyndromic sensorineural deafness in Africa. N Engl J Med 1998, 338:548-550.

20. Green GE, Scott DA, McDonald JM, Woodworth GG, Sheffield VC, Smith RJ: Carrier rates in the midwestern United States for GJB2 mutations causing inherited deafness. JAMA 1999, 281:2211-2216.

21. Morell RJ, Kim HJ, Hood L, Goforth L, Friderici K, Fisher R, Van Camp G, Berlin $\mathrm{Cl}$, Oddoux C, Ostrer $\mathrm{H}$, et al: Mutations in the connexin 26 gene (GJB2) among Ashkenazi Jews with nonsyndromic recessive deafness. N Engl J Med 1998, 339:1500-1505.

22. Sobe T, Erlich P, Berry A, Korostichevsky M, Vreugde S, Avraham KB, BonneTamir B, Shohat M: High frequency of the deafness-associated 167delT mutation in the connexin 26 (GJB2) gene in Israeli Ashkenazim. Am J Med Genet 1999, 86:499-500.

23. Sobe $T$, Vreugde $S$, Shahin $H$, Berlin $M$, Davis $N$, Kanaan M, Yaron $Y$, Orr-Urtreger A, Frydman M, Shohat M, Avraham KB: The prevalence and expression of inherited connexin 26 mutations associated with nonsyndromic hearing loss in the Israeli population. Hum Genet 2000, 106:50-57.

24. Kudo T, Ikeda K, Oshima T, Kure S, Tammasaeng M, Prasansuk S, Matsubara Y: GJB2 (connexin 26) mutations and childhood deafness in Thailand. Otol Neurotol 2001, 22:858-861.

25. Wang YC, Kung CY, Su MC, Su CC, Hsu HM, Tsai CC, Lin CC, Li SY: Mutations of Cx26 gene (GJB2) for prelingual deafness in Taiwan. Eur J Hum Genet 2002, 10:495-498.

26. Yan D, Park HJ, Ouyang XM, Pandya A, Doi K, Erdenetungalag R, Du LL, Matsushiro N, Nance WE, Griffith AJ, Liu XZ: Evidence of a founder effect for the 235delC mutation of GJB2 (connexin 26) in east Asians. Hum Genet 2003, 114:44-50.

27. Fischel-Ghodsian N: Mitochondrial mutations and hearing loss: paradigm for mitochondrial genetics. Am J Hum Genet 1998, 62:15-19.

28. Yao J, Lu Y, Wei Q, Cao X, Xing G: A systematic review and meta-analysis of 235delC mutation of GJB2 gene. J Trans/ Med 2012, 10:136.

29. Guo YF, Liu XW, Guan J, Han MK, Wang DY, Zhao YL, Rao SQ, Wang QJ: GJB2, SLC26A4 and mitochondrial DNA A1555G mutations in prelingual deafness in Northern Chinese subjects. Acta Otolaryngol 2008, 128:297-303.

30. Jun Al, McGuirt WT, Hinojosa R, Green GE, Fischel-Ghodsian N, Smith RJ: Temporal bone histopathology in connexin 26-related hearing loss. Laryngoscope 2000, 110:269-275.

31. Hwa HL, Ko TM, Hsu CJ, Huang CH, Chiang YL, Oong JL, Chen CC, Hsu CK: Mutation spectrum of the connexin 26 (GJB2) gene in Taiwanese patients with prelingual deafness. Genet Med 2003, 5:161-165.

32. Abe S, Usami S, Shinkawa H, Kelley PM, Kimberling WJ: Prevalent connexin 26 gene (GJB2) mutations in Japanese. J Med Genet 2000, 37:41-43.

33. Yang XL, Bai-Cheng X, Chen XJ, Pan-Pan B, Jian-Li M, Xiao-Wen L, Zhang ZW, Wan D, Zhu YM, Guo YF: Common molecular etiology of patients with nonsyndromic hearing loss in Tibetan, Tu nationality, and Mongolian patients in the northwest of China. Acta Otolaryngol 2013, 133(9):930-934.

34. Sagong B, Baek Jl, Oh SK, Na KJ, Bae JW, Choi SY, Jeong JY, Choi JY, Lee SH, Lee KY, Kim UK: A rapid method for simultaneous screening of multigene mutations associated with hearing loss in the Korean population. PLoS One 2013, 8:e57237.

35. Fugazzola L, Cerutti N, Mannavola D, Crino A, Cassio A, Gasparoni P, Vannucchi G, Beck-Peccoz P: Differential diagnosis between Pendred and pseudo-Pendred syndromes: clinical, radiologic, and molecular studies. Pediatr Res 2002, 51:479-484.

36. Yao G, Li S, Chen D, Wang H, Zhang J, Feng Z, Guo L, Yang Z, Yang S, Sun C, et al: Compound heterozygous mutations of SLC26A4 in 4 Chinese families with enlarged vestibular aqueduct. Int J Pediatr Otorhinolaryngol 2013, 77:544-549.

37. Jiang $L$, Feng $Y$, Chen $H, H e C$, Mei L: An investigation of SLC26A4 gene mutation in nonsydromic hearing impairment in Hunan province of China. Lin Chung Er Bi Yan Hou Tou Jing Wai Ke Za Zhi 2010, 24:587-591.

38. Huang $S$, Han D, Yuan $Y$, Wang G, Kang D, Zhang X, Yan X, Meng X, Dong $M$, Dai P: Extremely discrepant mutation spectrum of SLC26A4 between Chinese patients with isolated Mondini deformity and enlarged vestibular aqueduct. J Trans/ Med 2011, 9:167. 
39. Dai P, Yu F, Han B, Liu X, Wang G, Li Q, Yuan Y, Liu X, Huang D, Kang D, et al: GJB2 mutation spectrum in 2,063 Chinese patients with nonsyndromic hearing impairment. J Transl Med 2009, 7:26.

40. Yuan $Y$, Zhang $X$, Huang $S$, Zuo L, Zhang G, Song $Y$, Wang G, Wang $H$, Huang D, Han D, Dai P: Common molecular etiologies are rare in nonsyndromic Tibetan Chinese patients with hearing impairment. PLoS One 2012, 7:e30720.

41. Chen Y, Tudi M, Sun J, He C, Lu HL, Shang Q, Jiang D, Kuyaxi P, Hu B, Zhang $\mathrm{H}$ : Genetic mutations in non-syndromic deafness patients of Uyghur and Han Chinese ethnicities in Xinjiang, China: a comparative study. J Transl Med 2011, 9:154.

42. Kim SY, Lee BY, Lim JH, Ryu HM, Yang JH, Chung JH, Han HW, Park SY: Determination of the carrier frequencies of selected GJB2 mutations in the Korean population. Int J Audiol 2011, 50:694-698.

43. Tsukada K, Nishio S, Usami S: Deafness Gene Study C: a large cohort study of GJB2 mutations in Japanese hearing loss patients. Clin Genet 2010, 78:464-470.

44. Park HJ, Shaukat S, Liu XZ, Hahn SH, Naz S, Ghosh M, Kim HN, Moon SK, Abe S, Tukamoto K, et al: Origins and frequencies of SLC26A4 (PDS) mutations in east and south Asians: global implications for the epidemiology of deafness. J Med Genet 2003, 40:242-248.

45. Tsukamoto K, Suzuki H, Harada D, Namba A, Abe S, Usami S: Distribution and frequencies of PDS (SLC26A4) mutations in Pendred syndrome and nonsyndromic hearing loss associated with enlarged vestibular aqueduct: a unique spectrum of mutations in Japanese. Eur J Hum Genet 2003, 11:916-922.

46. Albert S, Blons H, Jonard L, Feldmann D, Chauvin P, Loundon N, SergentAllaoui A, Houang M, Joannard A, Schmerber S, et al: SLC26A4 gene is frequently involved in nonsyndromic hearing impairment with enlarged vestibular aqueduct in Caucasian populations. Eur J Hum Genet 2006, 14:773-779.

47. Rendtorff N, Schrijver I, Lodahl M, Rodriguez-Paris J, Johnsen T, Hansen E, Nickelsen L, Tumer Z, Fagerheim T, Wetke R, Tranebjaerg L: SLC26A4 mutation frequency and spectrum in 109 Danish Pendred syndrome/ DFNB4 probands and a report of nine novel mutations. Clin Genet 2013, 84(4):388-391.

48. Malik SG, Pieter N, Sudoyo H, Kadir A, Marzuki S: Prevalence of the mitochondrial DNA A1555G mutation in sensorineural deafness patients in island Southeast Asia. J Hum Genet 2003, 48:480-483.

doi:10.1186/1479-5876-11-312

Cite this article as: Xin et al:: Genetic mutations in nonsyndromic deafness patients of Chinese minority and han ethnicities in Yunnan, China. Journal of Translational Medicine 2013 11:312.

\section{Submit your next manuscript to BioMed Central and take full advantage of:}

- Convenient online submission

- Thorough peer review

- No space constraints or color figure charges

- Immediate publication on acceptance

- Inclusion in PubMed, CAS, Scopus and Google Scholar

- Research which is freely available for redistribution

Submit your manuscript at www.biomedcentral.com/submit
Ciomed Central 